\title{
A CRITICAL PERIOD FOR THE RECOVERY OF SOUND LOCALIZATION ACCURACY FOLLOWING MONAURAL OCCLUSION IN THE BARN OWL ${ }^{1}$
}

\author{
ERIC I. KNUDSEN, ${ }^{2}$ PHYLLIS F. KNUDSEN, AND STEVEN D. ESTERLY \\ Department of Neurobiology, Stanford University School of Medicine, Stanford, California 94305
}

Received September 2, 1983; Accepted November 23, 1983

\begin{abstract}
We studied the ability of barn owls to recover accurate sound localization after being raised with one ear occluded. Most of the owls had ear plugs inserted before they reached adult size, and therefore they never experienced normal adult localization cues until their ear plugs were removed. Upon removal of their ear plugs, these owls exhibited large systematic sound localization errors. The rate at which they recovered accurate localization decreased with the age of the bird at the time of plug removal, and recovery essentially ceased when owls reached 38 to 42 weeks of age. We interpret this age as the end of a critical period for the consolidation of associations between auditory cues and locations in space. Owls that had experienced adult localization cues for a short period of time before ear plugging recovered normal accuracy rapidly, even if they remained plugged well past the end of the critical period. This suggests that a brief exposure to normal adult cues early in the critical period is sufficient to enable the recovery of localization accuracy much later in life.
\end{abstract}

Barn owls localize sounds by associating small differences in the timing and intensity of sound at the two ears with locations in space (Knudsen and Konishi, 1979; Moiseff and Konishi, 1981). These binaural difference cues and their correlations with sound locations can be severely disrupted by occluding one ear. Young owls subjected to monaural occlusion adjust to the abnormal cues and learn to localize sounds accurately, but only if the occlusion is imposed within the first 60 days of life (Knudsen et al., 1982a).

In this study we investigate the ability of owls that have adjusted to early monaural occlusion to recover normal localization accuracy after the ear plug is removed. By removing ear plugs at various ages we reveal the effects of exposing the auditory system to abnormal sensory input over various periods of early development. We find that the rate at which localization accuracy is recovered slows with age, and that beyond about 9 months of age the capacity to recover is lost or substantially impeded.

\footnotetext{
We wish to thank Any Jelliffe and Philip Duncan for their assistance in training and testing owls, and John Middlebrooks, Carla Shatz, and Masakazu Konishi for reviewing the manuscript. This research was supported by Grant 1-863 from the March of Dimes and by National Institutes of Health Grants 2 R01 NS16099-04 and 1 T32 MH17047-01.

${ }^{2}$ To whom correspondence should be addressed.
}

\section{Materials and Methods}

Eleven barn owls (Tyto alba) served as experimental subjects. Each was taken from the nest at 7 to 12 days post-hatching and had a foam rubber ear plug (E.A.R., Cabot Corp.) sutured into the right (6 birds) or left (5 birds) auditory canal between 27 and 55 days of age (Table I). These birds regained normal sound localization with the ear plug in place (Knudsen et al., 1984). For this study, the ear plugs were removed at various ages and the sound localization error that resulted was measured periodically over the following weeks or months.

The experimental conditions and the methods used to measure sound localization are described in the previous paper (Knudsen et al., 1984). Briefly, the experiments were conducted in a darkened sound isolation chamber. The owls were trained to orient their heads toward movable auditory and visual stimuli; the auditory target consisted of repetitive noise bursts, and the visual target was a small dim light. A testing session consisted of 15 to 25 orientation responses to sound and a similar number to light stimuli. A difference in an owl's responses to sounds and lights indicated a sound localization error, since normal owls orient identically to both stimuli.

Head orientations were expressed in degrees of azimuth (left-right) and degrees of elevation (up-down) relative to the location of the stimulus. Two sets of data resulted from each testing session, one for responses to 
TABLE I

Summary of auditory histories and experimental results of all owls

\begin{tabular}{|c|c|c|c|c|c|c|c|c|c|}
\hline Owl & $\begin{array}{c}\text { Ear } \\
\text { Plugged }\end{array}$ & $\underset{\text { Plug }}{\text { Inserted }}$ & $\begin{array}{c}\text { Plug } \\
\text { Removed }\end{array}$ & \multicolumn{2}{|c|}{ Initial Location Errors } & \multicolumn{2}{|c|}{$\begin{array}{c}\text { Average Rate of Adjust- } \\
\text { ment }\end{array}$} & \multicolumn{2}{|c|}{$\begin{array}{c}\text { Time to Recover Preci- } \\
\text { sion }\end{array}$} \\
\hline & & \multicolumn{2}{|c|}{ days old } & \multicolumn{2}{|c|}{ degrees } & \multicolumn{2}{|c|}{ degrees/day } & \multicolumn{2}{|c|}{ days } \\
\hline 2 & $\mathrm{~L}$ & 35 & 90 & L 6.7 & -14.0 & 0.37 & 0.43 & 0 & 0 \\
\hline 3 & $\mathrm{R}$ & 29 & 109 & R 6.4 & +5.0 & 0.49 & 1.00 & 8 & 0 \\
\hline 4 & $\mathrm{~L}$ & 27 & 113 & L 6.7 & -18.4 & 0.36 & 0.62 & 2 & 21 \\
\hline 7 & $\mathrm{R}$ & 45 & 202 & $\mathrm{R} 14.4$ & +9.5 & 0 & 0.17 & 0 & $>148$ \\
\hline 8 & $\mathrm{~L}$ & 29 & 250 & L 11.7 & -23.1 & 0.28 & 0 & 0 & $>150$ \\
\hline 9 & $\mathrm{R}$ & 31 & 261 & R 13.4 & +4.1 & 0 & 0.03 & 0 & 27 \\
\hline 10 & $\mathrm{R}$ & 55 & 264 & R 6.2 & +8.3 & 0.53 & 0.55 & 0 & 0 \\
\hline 11 & $\mathrm{~L}$ & 54 & 339 & L 11.4 & -17.3 & 0.49 & 0.48 & 1 & 0 \\
\hline
\end{tabular}

sounds and the other for responses to lights, and a mean and standard deviation were computed for each data set. The difference between the means was taken as the sound localization error, a measure of accuracy. The standard deviation of the responses to sounds represents the reliability or precision of sound localization. Localization accuracy and precision were calculated for both azimuth and elevation.

The accuracy and precision of normal barn owls are described in the previous paper (Knudsen et al., 1984). Based on these data, errors greater than $3^{\circ}$ in azimuth or elevation and standard deviations greater than $3.0^{\circ}$ in azimuth or $3.7^{\circ}$ in elevation are regarded as abnormal. For owls with abnormally high standard deviations, i.e., poor precision, a linear regression of responses onto speaker locations was performed to test whether the owl was localizing the sound stimulus (Knudsen et al., 1984).

Average rates of adjustment were calculated by dividing an owl's initial sound localization error by the number of days required to bring the error to within the criterion value of $3^{\circ}$ in two successive testing sessions. Owls that never achieved this criterion level of accuracy were assigned average adjustment rates of zero.

\section{Results}

Initial effects of plug removal. Each of the owls had one ear plugged prior to 56 days of age (Table I). All of them adjusted their sound localization to normal levels of accuracy. When the ear plugs were removed at ages between 76 and 339 days, each bird initially exhibited a large sound localization error. The direction of the error depended on which ear had been occluded (Fig. 1): unplugging the right ear caused an owl to orient to the right and above the sound target, while unplugging the left ear caused it to orient to the left and below the target. The vertical component of these errors is due to the physical asymmetry of the owl's external ears, which makes the right ear more sensitive to sounds from above the horizontal plane and the left ear more sensitive to sounds from below the horizontal plane (Payne, 1971; Knudsen and Konishi, 1979). The magnitude of the error produced also differed depending on which ear had been plugged (Fig. 1). Removal of a right ear plug resulted in errors with approximately equal horizontal and vertical com-

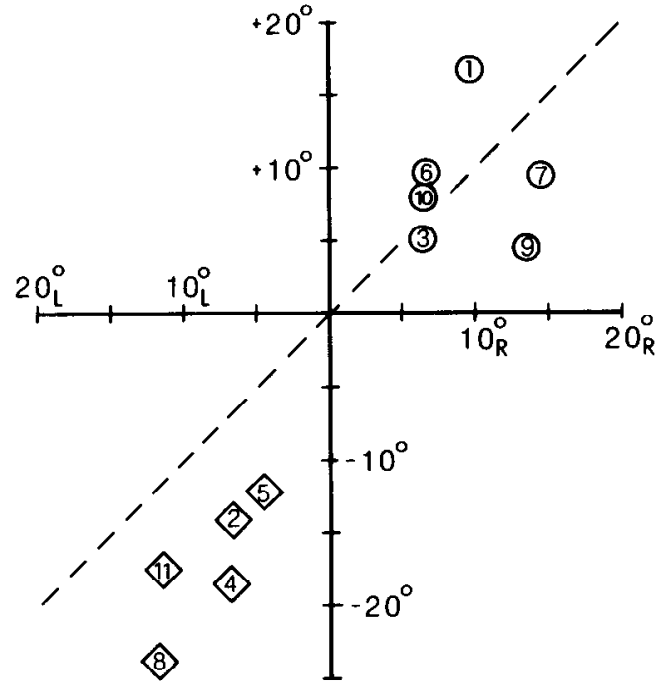

Figure 1. Initial sound localization errors for each owl following ear plug removal. Circles represent birds that had their right ears plugged; diamonds represent birds that had their left ears plugged. The numbers identify the individual owls (Table I). These errors were taken from the first testing session after plug removal in which the owl localized sounds in azimuth and elevation. The dashed line indicates errors having equal azimuth and elevation components.

ponents (average error: $9.5^{\circ}$ in azimuth and $8.5^{\circ}$ in elevation), whereas removal of a left ear plug resulted in errors with larger vertical than horizontal components (average error: $8.2^{\circ}$ in azimuth and $14.2^{\circ}$ in elevation).

Recovery of localization accuracy. The ability of owls to recover normal accuracy following ear plug removal persisted much later in development than the ability to adjust to the abnormal conditions caused by plug insertion (Fig. 2). The sensitive period for adjusting sound localization accuracy when an ear is occluded ends relatively abruptly at 55 to 60 days of age (Knudsen et al., 1984); when an ear plug is implanted beyond this age, owls do not adjust their localization errors. However, birds that were plugged prior to the end of the sensitive period, and therefore had adjusted to the abnormal cues, readjusted their sound localization accuracy rapidly when the ear plug was removed at ages well beyond 60 days. 


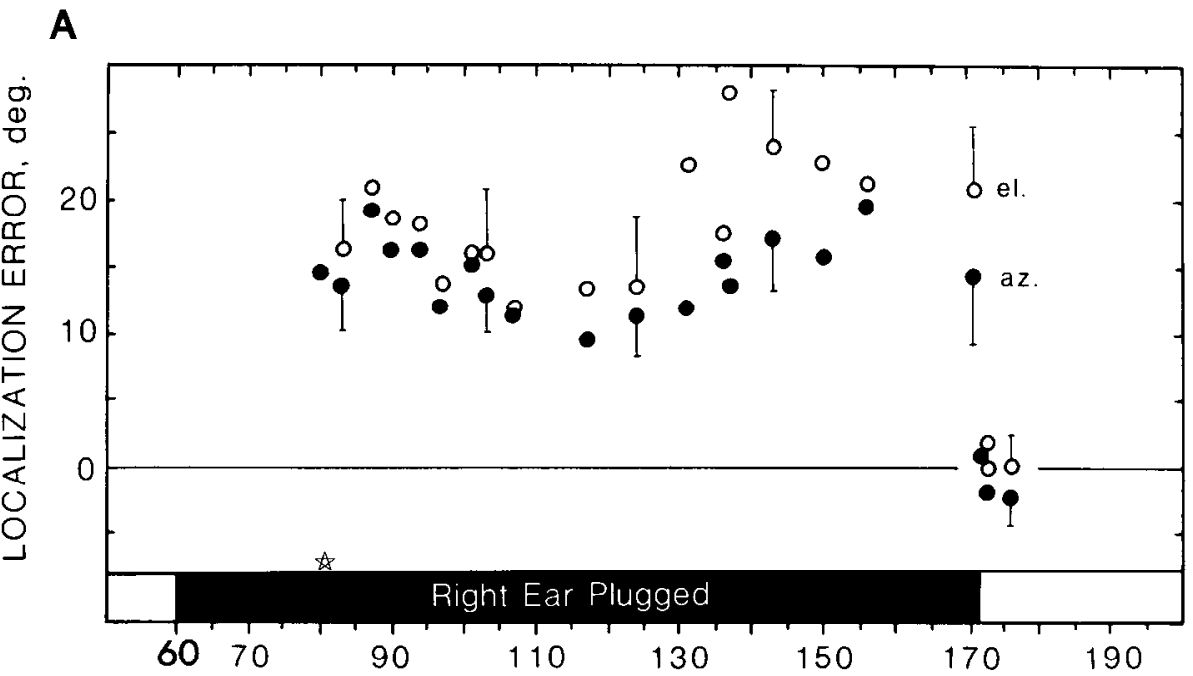

B

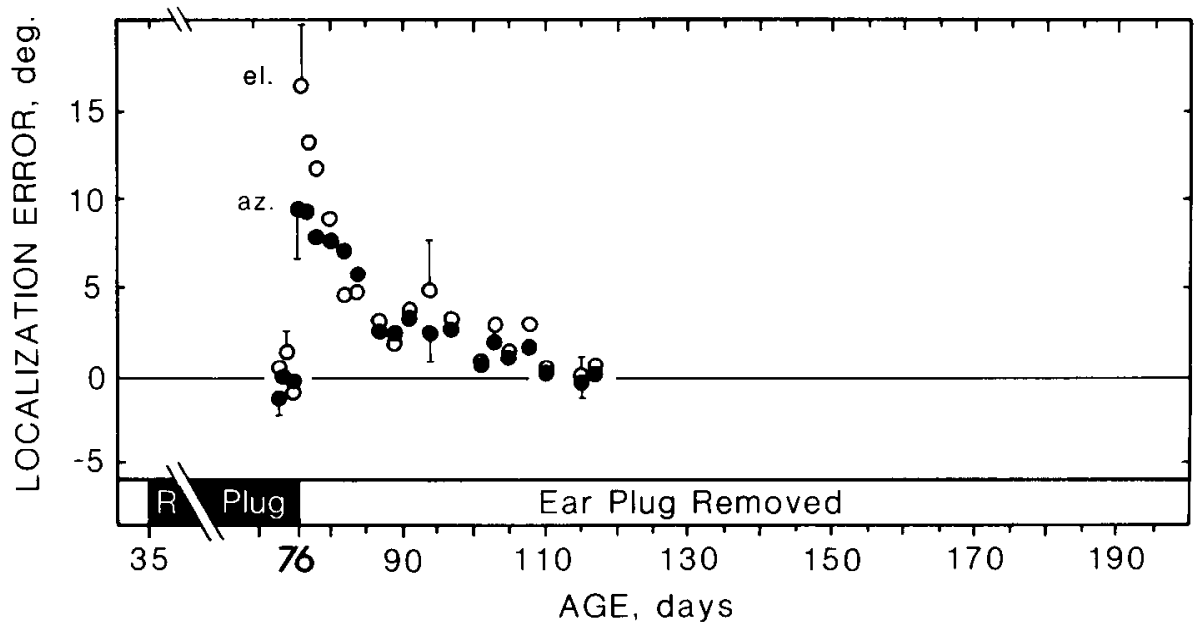

Figure 2. Sound localization errors plotted as a function of time for owls plugged $(A)$ and unplugged $(B)$ at similar ages. The owl in $A$ had its right ear plugged at 60 days of age and did not adjust to the abnormal cues (these data are from the previous study; Knudsen et al., 1984). The owl in $B$, owl 1, had its right ear plug removed slightly later, at 76 days of age, but it readjusted rapidly to the normal cues. The azimuth $(O)$ and elevation $(O)$ components of the localization errors are plotted separately in each graph. Representative standard error bars are shown periodically. The star at the bottom of the graph in $A$ indicates a day in which the owl did not localize sounds in elevation (see "Materials and Methods").

The rate and extent of recovery of sound localization accuracy decreased with the age of the bird at the time of plug removal. Sound localization errors were corrected most rapidly and completely by four owls that had their ear plugs removed before 20 weeks of age (Table I; owls 1 to 4). The horizontal component of their errors decreased at average rates of $0.36^{\circ}$ to $0.58^{\circ}$ per day until it was less than the $3^{\circ}$ criterion for normal accuracy (Figs. $3 A$ and 5 ). Owl 3 continued to improve its accuracy in azimuth at this rapid rate and had an error of $0.3^{\circ}$ only 10 days after its plug was removed. Owls 1,2 , and 4 slowed their rates of adjustment when their errors reached $2^{\circ}$ to $3^{\circ}$. However, by 4 weeks after plug removal the azimuth errors of all these birds were less than $2^{\circ}$ and indistinguishable from those of normal birds.

The vertical component of the errors of these birds decreased in a similarly rapid fashion (Figs. $4 A$ and 5). The initial rate of adjustment was particularly steep: $1.0^{\circ}$ to $2.0^{\circ}$ per day. Owl 3 , which had only a $5^{\circ}$ error to start with, was within criterion accuracy after 1 day and had corrected its error to $0.1^{\circ}$ in 5 days. The other three birds had much larger elevation errors of $14.0^{\circ}$ to $18.4^{\circ}$. These owls rapidly adjusted the first $7^{\circ}$ to $11^{\circ}$ of error at the rapid rate; then their rates of adjustment slowed by more than one-half to $0.2^{\circ}$ to $0.5^{\circ}$ per day. Their errors continued to decrease at this slower rate until the errors completely disappeared 4 to 5 weeks after plug removal. Average rates of adjustment in elevation ranged from $0.43^{\circ}$ to $1.00^{\circ}$ per day.

Owls 5 and 6 were older when their ear plugs were removed (Table I), and they corrected their sound localization errors more slowly (Figs. $3 B, 4 B$, and 5). Both birds had small azimuth errors to begin with, and they adjusted these at average rates of approximately $0.28^{\circ}$ per day (Table I). Neither bird was able to localize sounds in elevation on the day the ear plug was removed. On subsequent days they exhibited large elevation errors which decreased over time in an erratic pattern. The 
irregularity of these time courses was due in some part to the birds' imprecision at localizing in elevation. Owl 5 adjusted its elevation error from $12.3^{\circ}$ to $3^{\circ}$ in 52 days, yielding an average rate of $0.18^{\circ}$ per day. Owl 6 adjusted its elevation error from $9.5^{\circ}$ to $3^{\circ}$ in 85 days for an average rate of $0.08^{\circ}$ per day (Fig. 5).

The five owls that had their ear plugs removed at ages greater than 28 weeks fell into two distinct groups based on the time course of their error adjustments (Figs. $3 C$, $4 C, 5$ and 8). Owls 7, 8, and 9, which were plugged at an early age (Table I), never recovered normal accuracy for as long as we tested them (21 to 26 weeks after plug removal). In contrast, owls 10 and 11 , which were plugged later, recovered normal accuracy quickly.

Although owls 7, 8, and 9 never learned to localize with normal accuracy after plug removal, each of them did correct its error to some extent (Figs. $3 C$ and $4 C$ ). They adjusted their horizontal errors at rates of approximately $0.3^{\circ}$ per day for the first 3 or 4 weeks after plug removal. In this time, owl 8 completely eliminated the azimuthal component of its error. The horizontal errors of the other two birds, although still large, stopped decreasing and remained relatively stable for the rest of the measurement period.

Owl 8 maintained a significant vertical error even though it eventually eliminated its horizontal error (Figs. $4 C$ and $7 B$ ). In the first 3 weeks following ear plug removal, this owl's elevation error dropped at a rate of about $0.9^{\circ}$ per day. However, its error never reached the criterion level for accuracy. Instead it stopped decreasing and began to fluctuate erratically around an average value of $5.0^{\circ}$. Three months later the error had increased to an average of $7.0^{\circ}$, where it remained for the duration of the measurement period (Fig. $7 B$ ). This bird was quite imprecise (average $\mathrm{SD}=4.4^{\circ}$ ) and never regained normal precision in elevation (Table I).

The adjustment of elevation errors by owls 7 and 9 followed different time courses (Fig. 4C). Owl 9 had an unusually small vertical error to start with, and it corrected this error gradually at a rate of $0.3^{\circ}$ per day. However, the error did not stabilize at zero but continued to descend until it became a significant error to the opposite side of the target.

Owl $7 \mathrm{had}$ a large initial elevation error that fluctuated radically between about $10^{\circ}$ and $2^{\circ}$ in successive testing sessions (Fig. $4 \mathrm{C}$ ). Although the precision of this bird in elevation was poor, its responses varied significantly with the location of the speaker (Fig. 6). Hence, this owl localized the sound, albeit imprecisely, on each of these days. After 38 days the elevation error of this owl remained within criterion accuracy in successive testing sessions. Using this date as the "time to adjust," an average rate of adjustment was calculated to be $0.17^{\circ}$ per day. Obviously, in this case an adjustment "rate" is artificial and does not reflect the nature of the adjustment process (hence the value appears in brackets in Fig. $5)$. In later testing sessions, this owl's elevation error continued to fluctuate unpredictably, even moving to the opposite side of the sound target (Fig. $4 C$ ). In addition, this owl never regained normal precision in elevation (average $\mathrm{SD}=4.6^{\circ}$ ). An interesting feature of this bird's responses is that they were quite precise and stable in azimuth (with an error), whereas they were imprecise and variable in elevation, indicating that localization accuracy and precision in each dimension can be adjusted independently.

A distinguishing characteristic shared by owls 7,8 , and 9 was that they never regained accurate sound localization. Owls 7 and 9 maintained errors in azimuth, while owl 8 maintained an error in elevation. It may be important here that owls 7 and 9 had their right ears plugged and owl 8 had its left ear plugged (Table I). The ages at which these owls stopped adjusting their localization errors were rather similar (Fig. 7): owls 7 and 9 stopped adjusting in azimuth at about 270 and 290 days, respectively, and owl 8 stopped adjusting in elevation at 272 days. This similarity is remarkable in that their ear plugs were removed at far more disparate ages (between 202 and 269 days). These data suggest that, at this age, a critical period was drawing to a close.

Owls 10 and 11 also had their ear plugs removed late in life. However, these owls, which had briefly experienced adult localization cues before the ear plugs were inserted, recovered normal accuracy and precision surprisingly quickly, with time courses that were indistinguishable from those of the youngest birds to be unplugged (Figs. 5 and 8). The localization errors of these birds decreased at average rates of about $0.5^{\circ}$ per day in azimuth and in elevation until they reached criterion levels. Furthermore, both owls localized with normal precision in azimuth and clevation within 1 day after plug removal (Table I).

Recovery of precision. Plug removal typically caused a deterioration of localization precision (Fig. 9). Precision in azimuth usually returned to normal within 2 days; precision in elevation took longer in most cases and sometimes required weeks to return to normal (Table I). Exceptions to these generalizations were owls 1 and 3, which regained normal precision more quickly in elevation than in azimuth, and owl 2, which localized with normal precision as soon as its ear plug was removed.

\section{Discussion}

The rate at which a barn owl recovers accurate sound localization after removal of an ear plug depends on age: owls that are younger than 20 weeks of age when the plug is removed recover quickly and completely, whereas owls that are older than 28 weeks of age at the time of plug removal recover slowly and may never regain accurate sound localization (Figs. 5 and 7). If an owl never experiences normal adult cues early in life, by the age of 38 to 42 weeks its already slow rate of adjustment slows even further or ceases altogether (Fig. 7). We propose this age as the end of a critical period during which the auditory system consolidates associations between binaural cues and locations of sounds in space. It may be significant that the end of the critical period coincides with the age at which barn owls reach sexual maturity (personal observation).

The ability of owls to recover sound localization accuracy following plug removal persists much later in life than does the ability to adjust accuracy after a plug is inserted (Fig. 2). This discrepancy indicates a strong bias 

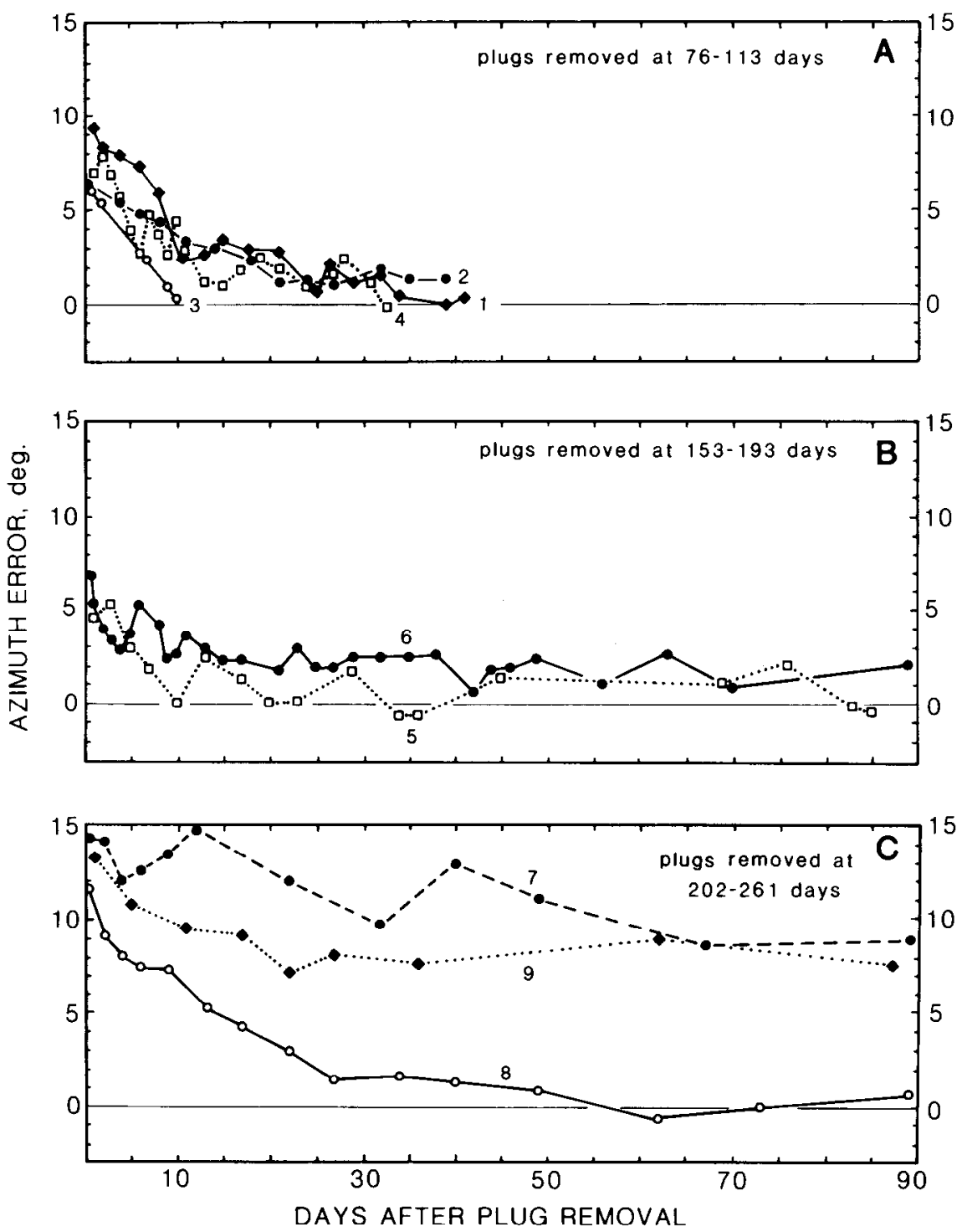

Figure 3. Time course of adjustment of horizontal sound localization errors following ear plug removal. All of these owls had been plugged before reaching adult size. Each line type represents data from one bird. The number associated with the line identifies the individual (Table I). The owls are grouped according to the age at which their ear plugs were removed. Older birds took longer to adjust or did not adjust at all. The data in $A$ are from owls 1 to 4 , which were unplugged between 76 and 113 days of age. The data in $B$ are from owls 5 and 6 , which had their ear plugs removed at 153 and 193 days, respectively. The data in $C$ are from owls 7 to 9 , which were unplugged between 202 and 261 days of age.

in the auditory system for the consolidation of associations between "normal" binaural cues and locations in space. This, in turn, implies that the auditory system has an innate expectation of what "normal" adult cues should be. Binaural values that are outside of this expected range (abnormal cues) are consolidated only if cues within the expected normal range are not experienced during the first 38 to 42 weeks of life (the critical period). A restoration of normal cues before the end of the critical period causes a rejection of the associations based on abnormal cues and a readjustment to the normal cues. Once this occurs, the auditory system cannot again adjust its associations to accommodate abnormal cues, even if the owl is still quite young and the same ear is replugged (Knudsen et al., 1984). It is as though the neuronal connections that underlie the abnormal associations are not readily stabilized, whereas those that form associations within the expected range are stabilized easily.

The exceptional impact of a brief early exposure to normal adult cues can be seen in the data from owls 10 and 11 (Fig. 8). These owls reached adult size at about 45 days of age (Knudsen et al., 1984). They experienced adult localization cues for only 10 days until they were monaurally occluded at 54 and 55 days of age, respectively. Fven though these birds remained occluded longer than any of the other birds, well past the end of the critical period, when their ear plugs were removed they recovered perfect localization accuracy and precision as swiftly as the youngest owls (Fig. 5). Their early exposure to normal adult cues apparently had a lasting effect on the development of their sound localization pathways. These data once again illustrate the strong bias in the auditory system for the acceptance of normal cues. 

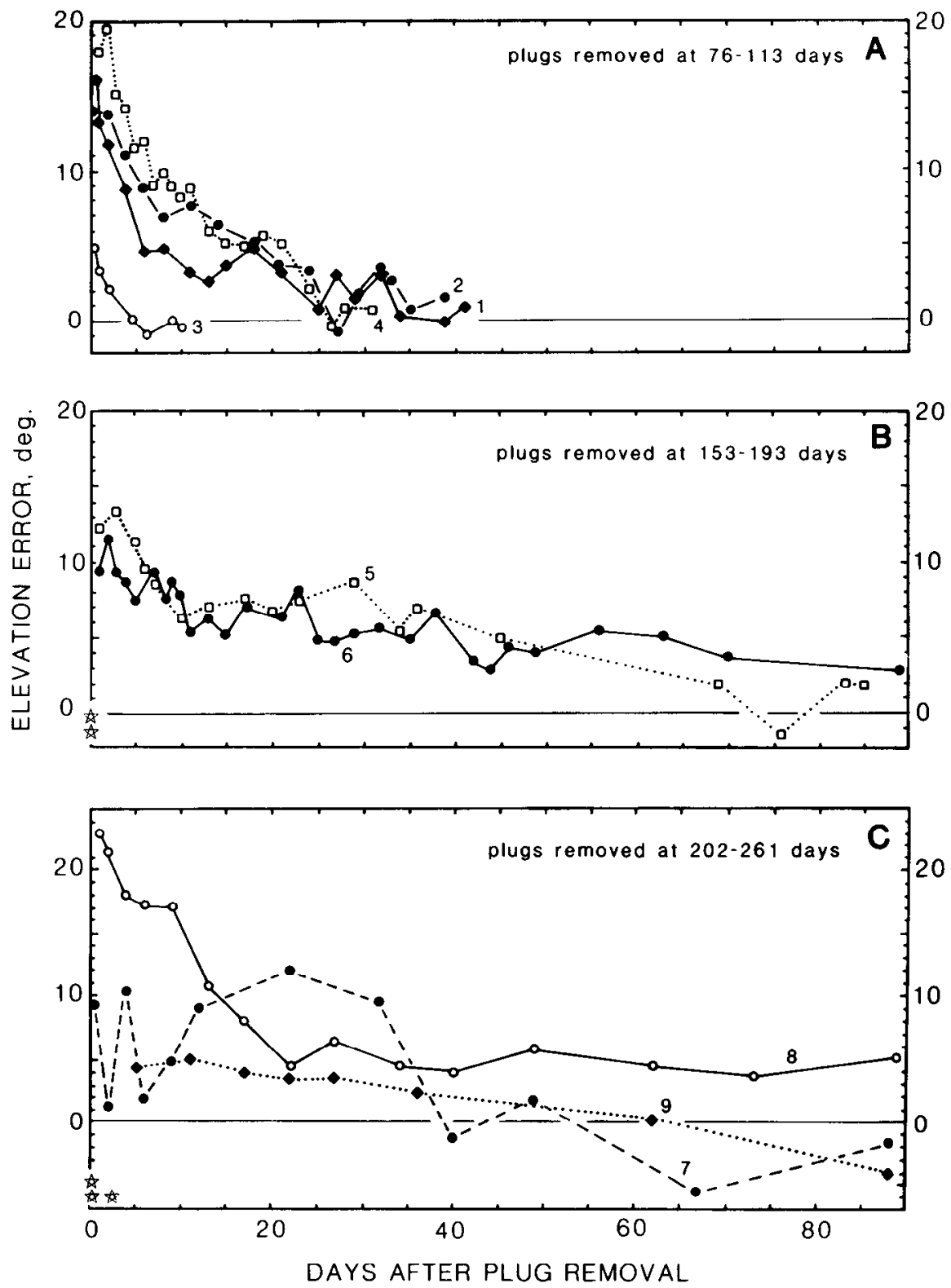

Figure 4. Time course of adjustment of vertical sound localization errors following ear plug removal. These data represent the elevation components of the errors from the owls shown in Figure 3. Stars indicate days on which an owl did not localize the sound in elevation (see "Materials and Methods").

Two periods in the development of sound localization have now been identified: (1) a sensitive period during which abnormal auditory cues alter sound localization, and (2) a critical period during which auditory cues become permanently associated with locations in space. It is possible that these periods are ended by different neural mechanisms, one mechanism limiting the ability of the auditory system to form abnormal connections and the other causing connections to become permanent. Another possibility is that both periods are ended by a single, experience-dependent mechanism. To trigger this mechanism, auditory experience would have to satisfy two criteria simultaneously and for a sufficient length of time: (1) sound localization cues must be within an "expected" range (as described above), and (2) the asso- ciations of these cues with locations in space must be correct (i.e., no localization error), perhaps validated by visual feedback (Knudsen et al., 1982b). The fact that there is a critical period for the recovery of sound localization accuracy suggests that if these criteria are never met, after 8 to 9 months the mechanism is triggered unconditionally. Our data do not discriminate between these possibilities, but we favor the latter because of its conceptual simplicity.

Comparisons with other critical periods. The critical period for recovery of sound localization accuracy shares many features with the critical period for song learning by songbirds. White-crowned sparrows, for example, must be exposed to conspecific song during the first 50 days post-hatching in order to develop normal song as 


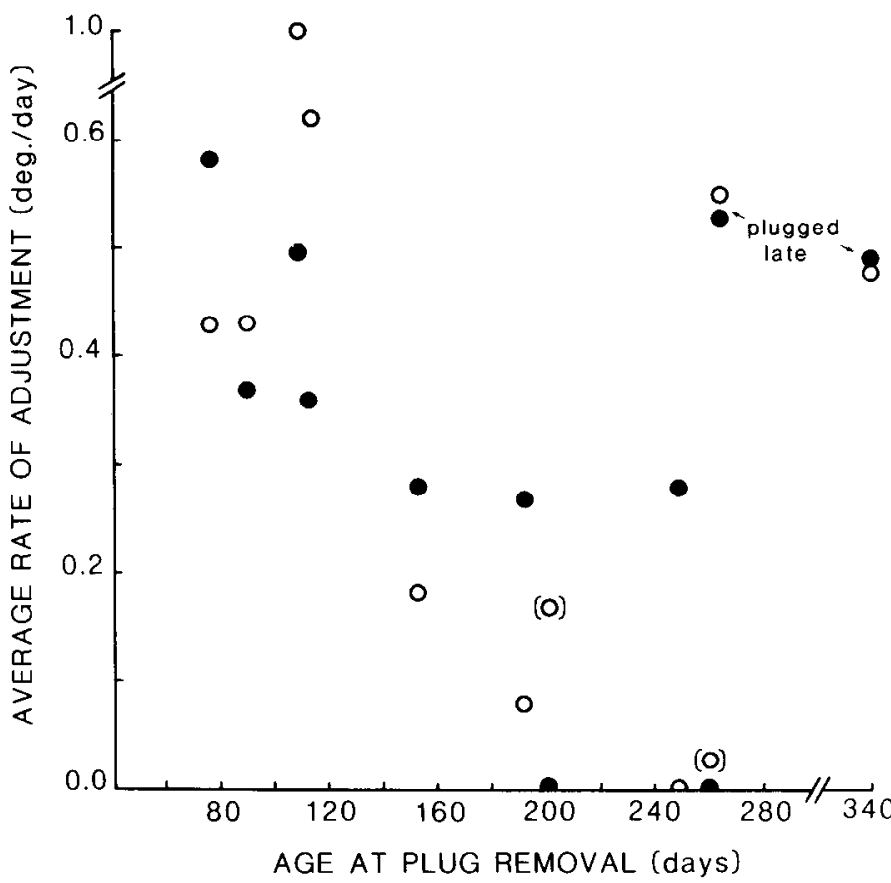

Figure 5. The average rate of error adjustment decreases with age. Each point represents the average rate of adjustment in azimuth (O) or elevation $(O)$ for each owl. The data from all birds are shown. Average rate was calculated by dividing an owl's initial error by the number of days required for the owl to localize with normal accuracy (error less than $3^{\circ}$ ) in two successive testing sessions. Localization errors that were never corrected (Figs. $3 C$ and $4 C$ ) were assigned average rates of zero. Owl 7 adjusted its elevation error in an erratic time course, and owls 7 and 9 never exhibited stable elevation errors; therefore, their rates for adjustment of elevation accuracy are shown in brackets. adults (Marler, 1970). These birds have an innate bias or "predisposition" to accept only songs that are within a restricted, normal range (Thorpe, 1961; Immelman, 1969; Marler, 1970; Marler and Peters, 1977; Konishi, 1978). Birds exposed only to abnormal song models or songs of other species sing as though they were raised in sound isolation, whereas relatively brief exposures to a normal song model, even in the constant presence of other song types, results in the development of normal song.

The visual system also goes through a number of critical periods during its development. For example, visual experience is necessary for the normal development of fundamental visual properties such as binocular interaction and sensitivity to binocular disparities and line orientations (Pettigrew et al., 1968; Cynader et al., 1976; Sherk and Stryker, 1976; Stryker, 1981; Levitt and Van Sluyters, 1982). Like the auditory system, the visual system also exhibits innate biases for the acceptance of certain ranges of "normal" input, as exemplified by the alignment of binocular receptive fields and the crude but clear line orientation preferences of neurons in the cortex of visually inexperienced animals. In contrast to the auditory system, just a few days of abnormal visual experience during the development of binocular interaction causes profound and long-lasting adverse effects in the visual system (Hubel and Wiesel, 1970; Mitchell et al., 1977), as though binocular interaction were an unstable state demanding constant and continuous validation to be maintained during development. This is quite different from the influence of auditory experience during the critical periods for song learning and sound localization, in which a brief exposure to normal stimuli can be sufficient to consolidate the neuronal circuitry underlying normal function.
A

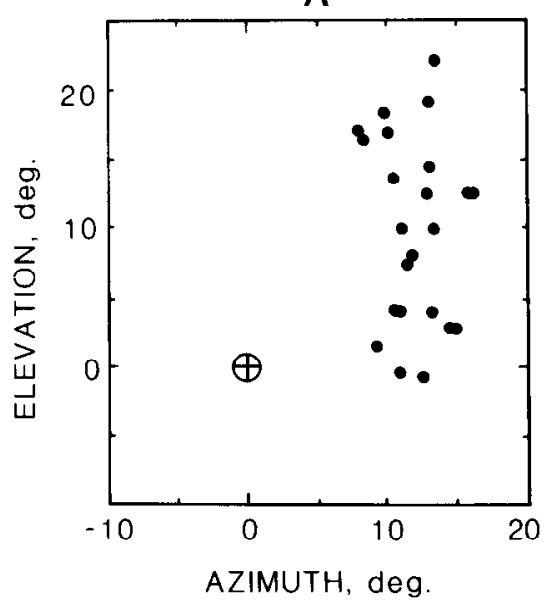

B

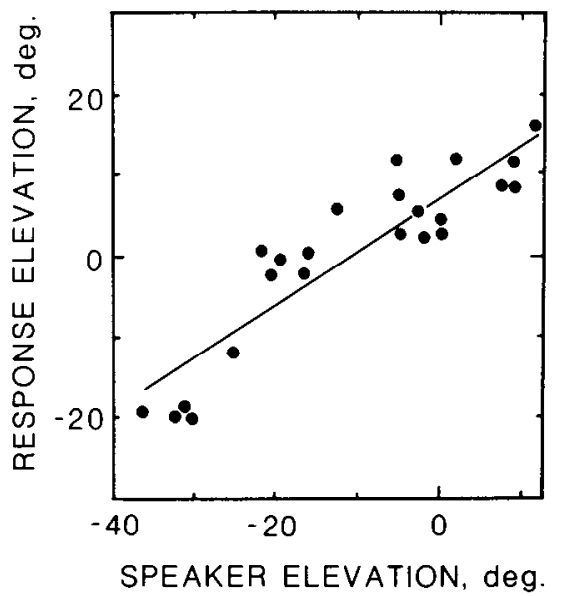

Figure 6. Auditory orientation responses of owl 7, four days after plug removal, showing precise but inaccurate localization in azimuth and imprecise and inaccurate localization in elevation. In $A$, responses ( ) are plotted in azimuth and elevation relative to the target's location $(\oplus)$. In $B$, the elevation of the responses is plotted against the elevation of the speaker for these same data. The slope of the regression line and the fit of the points to the line demonstrates that the owl was localizing sounds in elevation despite the large scatter seen in $A$. 

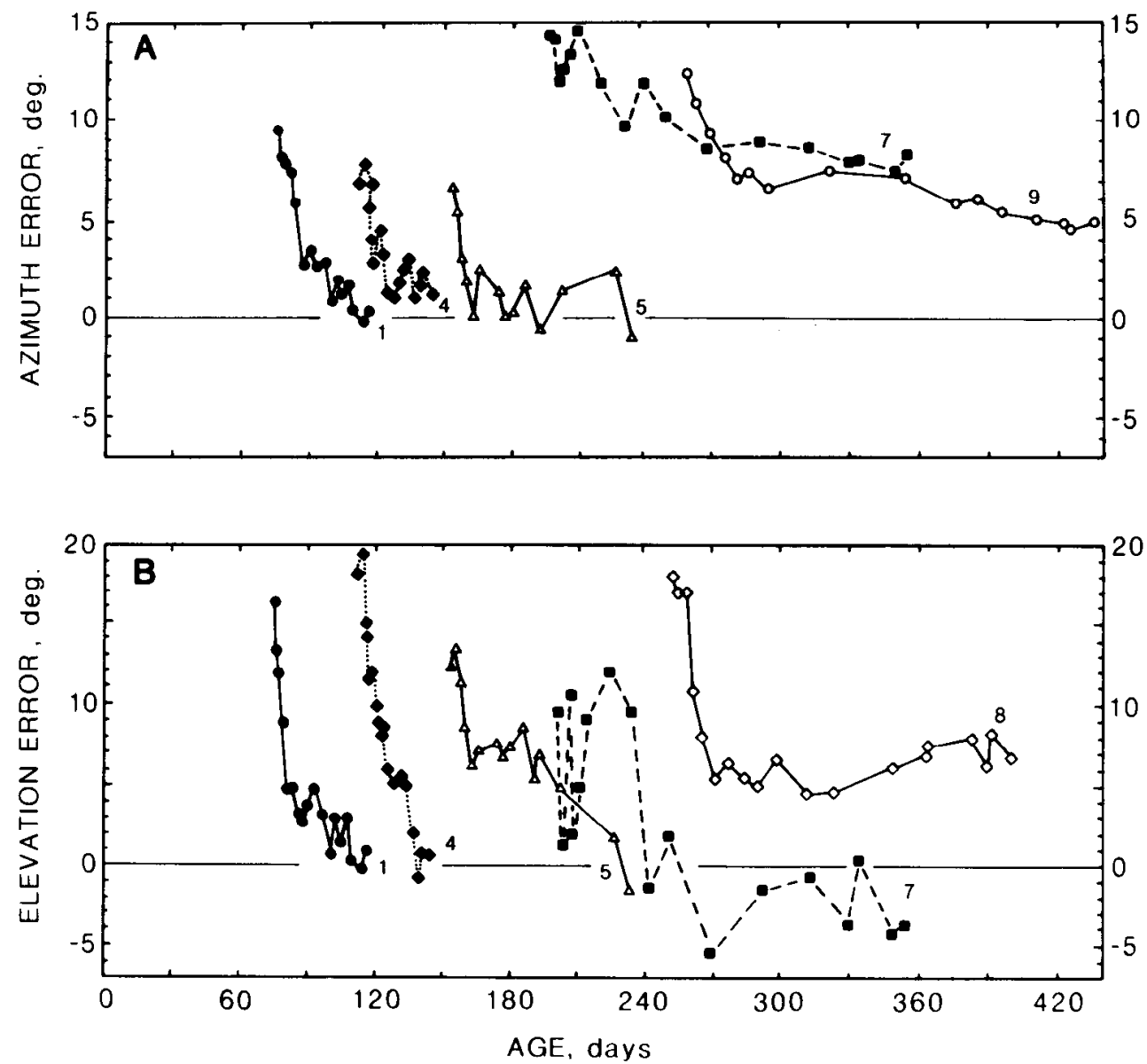

Figure 7. Adjustment of sound localization error as a function of age. All of these birds were pluggea perore they reached adult size. In $A$, the time courses for correcting azimuth errors are shown for five owls that were unplugged at various ages. Each line type represents data from a single owl; the number associated with each line identifies the owl (Table I). Owls 7 and 9 never recovered accuracy in azimuth. In $B$, the time courses for correcting elevation errors are plotted for five owls. The data are from the same birds as in $A$, with the exception that owl 8 has replaced owl 9. Owl 8 never regained accuracy in elevation.

A

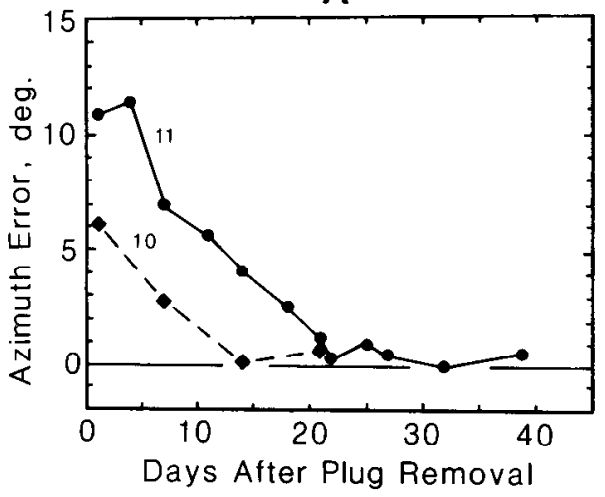

B

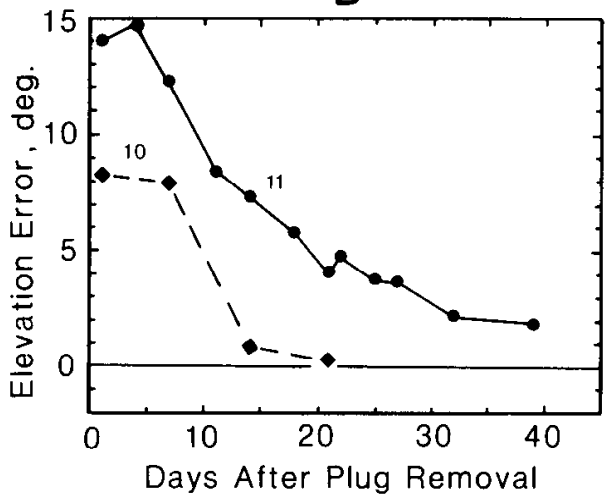

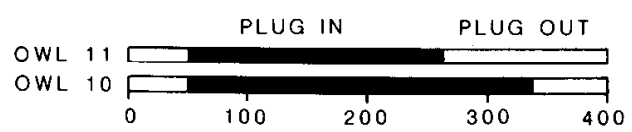

Figure 8. Adjustment of sound localization errors following ear plug removal by birds that had been plugged after reaching adult size. In $A$, the azimuth errors of owls 10 and 11 are plotted; in $B$, the elevation components of their errors are plotted. Owls 10 and 11 had ear plugs inserted at 55 and 54 days, respectively, and had their plugs removed at 264 and 339 days of age, as indicated by the bars below the graphs. Although the ages of these birds at plug removal are past the end of the critical period, these birds adjusted their errors as rapidly as the youngest birds. 


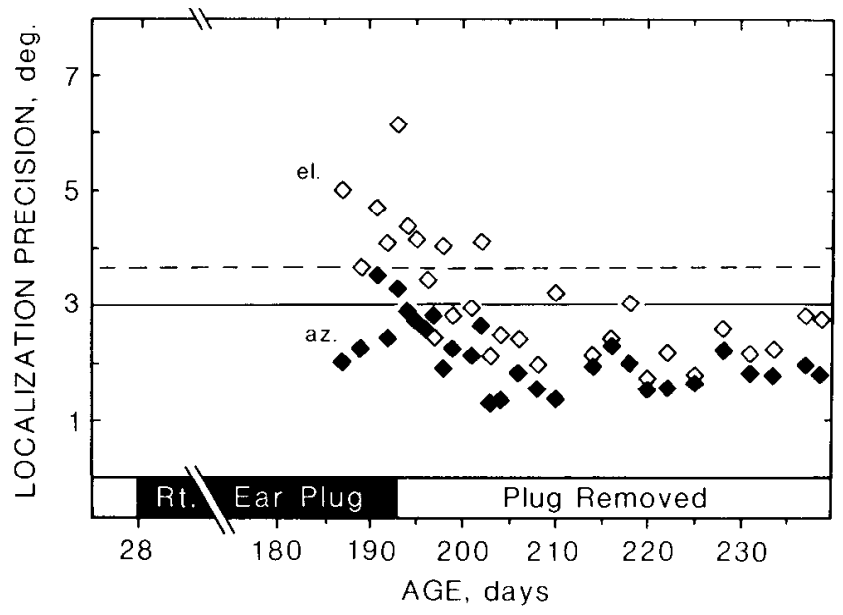

Figure 9. The effect of ear plug removal on the precision of sound localization for owl 6. Localization precision is quantified in terms of standard deviations of orientations to sound. Precision in azimuth $(\diamond)$ and elevation $(\diamond)$ are plotted separately. Our criterion values for normal precision are indicated by a solid line for azimuth and a dashed line for elevation. The bar along the bottom of the graph represents the auditory history of the bird.

\section{References}

Cynader, M., N. Berman, and A. Hein (1976) Recovery of function in cat visual cortex following prolonged visual deprivation. Exp. Brain Res. 25: 139-156.

Hubel, D. H., and T. N. Wiesel (1970) The period of susceptibility to the physiological effects of unilateral eye closure in kittens. J. Physiol. (Lond.) 202: 419-436.

Immelman, K. (1969) Song development in the zebra finch and other estrildid finches. In Bird Vocalizations, R. A. Hinde, ed., pp. 61-74, Cambridge University Press, London.

Knudsen, E. I., and M. Konishi (1979) Mechanisms of sound localization by the barn owl (Tyto alba). J. Comp. Physiol. 133: 13-21.
Knudsen, E. I., P. F. Knudsen, and S. D. Esterly (1982a) Farly auditory experience modifies sound localization in barn owls. Nature 295: 238-240.

Knudsen, E. I., P. F. Knudsen, and S. D. Esterly (1982b) Sound localization is adjusted according to visual space in owls. Soc. Neurosci. Abstr. 8: 751.

Knudsen, E. I., S. D. Esterly, and P. F. Knudsen (1984) Monaural occlusion alters sound localization during a sensitive period in the barn owl. J. Neurosci. 4: 1001-1011.

Konishi, M. (1978) Auditory environment and vocal development in birds. In Perception and Experience, R. D. Walk and H. L. Pick, eds., pp. 105-118, Plenum Publishing Corp., New York.

Levitt, F. B., and R. C. Van Sluyters (1982) Recovery of binocular function in kitten visual cortex. J. Neurophysiol. 48: 1336-1346.

Marler, P. (1970) A comparative approach to vocal learning: Song development in white-crowned sparrows. J. Comp. Physiol. Psychol. Monogr. 71: 1-25.

Marler, P., and S. Peters (1977) Selective vocal learning in a sparrow. Science 198: 519-521.

Mitchell, D. E., M. Cynader, and J. A. Movshon (1977) Recovery from the effects of monocular deprivation in kittens. J. Comp. Neurol. 176: 53-64.

Moiseff, A., and M. Konishi (1981) Neuronal and behavioral sensitivity to binaural time differences in the owl. J. Neurosci. 1: 40-48.

Payne, R. S. (1971) Acoustic location of prey by barn owls (Tyto alba). J. Exp. Biol. 54: 535-573.

Pettigrew, J. D., T. Nikara, and P. O. Bishop (1968) Binocular interaction on single units in cat striate cortex: Simultaneous stimulation by single moving slit with receptive fields in correspondence. Exp. Brain Res. 6: 391-416.

Sherk, H., and M. P. Stryker (1976) Quantitative study of cortical orientation selectivity in visually inexperienced kitten. J. Neurophysiol. 39: 63-70.

Stryker, M. P. (1981) Late segregation of geniculate afferents to the cat's visual cortex after recovery from binocular impulse blockade. Soc. Neurosci. Abstr. 7: 842.

Thorpe, W. H. (1961) Bird Song, Cambridge University Press, London. 